the first tasks would have been a careful study of the literature of the subject and particularly of the results already obtained from the experiments in the art of ruling which have been made in other countries. This procedure, however, does not appear to have been followed. Even the Commission which recently worked under the able guidance of Sir John Simon was not empowered to study constitutional developments in other Asiatic countries, otherwise " they might well have hesitated before recommending even a moderate extension of the franchise". The matter, however, has gone too far for such studies to be undertaken. The new constitution will shortly be established : the results will soon be clear to all. If it succeeds, all criticism will be laid to rest by the one unanswerable argument--success. If it fails, a new Indian Civil Service, in which it is hoped that science will take its proper place, will have to be re-established.

\section{A High-Efficiency Gaseous Lamp}

MessRs. Philips Lamps, Ltd., are introducing a new lamp which has an efficiency of about eight times that of a gas-filled lamp taking the same power. A description of the lamp is given in the Electrical Times for July 14. In the new lamp an electric discharge passes through a rare gas ' filling ' with a small quantity of metallic sodium. There is an oxide cathode with one or two anodes. The bulb of the lamp is in the shape of a cylinder, which has to be heated up to a certain temperature sufficient to vaporise the sodium. The lamp is enclosed in a second cylinder, which accelerates the heating and keeps the temperature constant. The discharge and consequently the emission of light depend mainly on the sodium vapour. The colour of the light is yellow and practically monochromatic. This colour is favourable to good visibility and therefore the lamp is very suitable for street lighting. A photograph taken at night is shown of a long length of road in Holland illuminated by the new gaseous lamps. It has been noticed that drivers of fast cars when entering the newly lighted part of the road switched off their headlights unasked. Hence there is no 'dazzle', the elimination of which is one of the greatest problems of night driving. The candlepower of the lamps is $500-600$ for the smallest size made, which take 100 watts. These lamps will be useful where colour is of minor importance. For domestic use a whiter light is more desirable.

\section{Modern Developments in Precision Clocks}

THE most accurate timekeepers of to-day are divided into two classes, depending on whether the restoring force of the oscillator is gravity, as in pendulum clocks, or elasticity, as in quartz crystal oscillators. In a monograph by A. L. Loomis and W. A. Marrison on precision clocks, published in the Transactions of the American Institute of Electrical Engineers, an account is given of the performance of a set of 100,000 -cycle quartz oscillators built by the Bell Telephone Laboratories for use as a primary frequency standard. The frequency of quartz oscillators is practically independent of the amplitude. They are not affected by gravity or magnetic fields and can be easily shielded from electrostatic fields. They are practically unaffected by heavy traffic in neighbouring roads or by the vibrations near earthquake zones. A crystal clock standard is more costly than a pendulum clock of the highest precision, but it can be used for many purposes. For example, an absolute comparison of crystal clocks can be made with an error of less than one hundred-thousandth part of a second, and can be maintained continuously. For short time comparisons an inaccuracy not greater than 1 in $10^{10}$ has been obtained. The high accuracy of comparison is due chiefly to the fact that the number of vibrations is 200,000 times greater than with a 'seconds' pendulum. A comparison made of the data obtained by observing the difference in the rates of a crystal clock and three pendulum clocks revealed for the first time a lunar day variation. This is due to the fact that the crystal does not respond to variations in the gravitational effect of the moon, while the pendulum does. The difference in the rates of the clock and the crystal timekeeper thus contains a term depending on the period of the lunar day.

\section{Jubilee of the Ferranti Works}

THe late Dr. S. Z. de Ferranti at the age of eighteen was the principal founder of the original company of Ferranti, Thomson and Ince in Charterhouse Square, London, in 1882. It is a little difficult to realise that there was then a great demand for electric meters. Messrs. Ferranti, Ltd., now of Hollinwood, Manchester, held an exhibition at Bush House, London, during June to commemorate their jubilee. The fifty years' life-story of the firm shown by the historical exhibits is largely a history of the development of public electricity supply. A particularly interesting exhibit was the earliest models of Ferranti meters, some of which have only recently been taken out of service. The new methods of hardening the pivots and burnishing them so as to get the exact shape with the help of a micrometer jewel examiner with a powerful microscope were shown in action. New devices rendered necessary by the 132-kilovolt grid scheme in Great Britain were shown in action. An even more recent development is the manufacture of electric clocks, which are now made quite cheaply, of all sizes and shapes with cases of bakelite, wood, or metal. A prominent feature of the radio exhibit was a new seven-valve receiving set. A full range of water heaters and fires were shown. A working model of the Ferranti hot-water system for a house employing those heaters was shown. The 'Era' fire which Ferranti's make is said to be ideal for devices for hatching chickens (chicken brooders). The machines used at the Ferranti works in Hollinwood are of the most modern design, and employ more than five thousand workmen.

\section{Tuberculosis in England and Wales}

The Report on Tuberculosis by Dr. A. S. MacNalty to the Ministry of Health (Reps. on Pub. Health and Med. Subjects, No. 64. H.M. Stationery Office. 3s. net.) may be regarded as an 'audit' of the present position of the tuberculosis question in Great Britain. Tuberculosis is a disease not only of medical interest but also of wide sociological and economic importance. Anti-tuberculosis measures cost the country a great deal; for example, some $2 \frac{1}{2}$ million 
pounds are expended annually on the maintenance of residential institutions for treatment. During twenty years of anti-tuberculosis campaign, the decline in the mortality from the disease has been striking-from a total of 53,120 deaths in 1911 to 35,745 in 1930 . One of the most interesting and important sections of this Report deals with the results of sanatorium treatment. This is very difficult to evaluate, for the ultimate result depends so much on a variety of factors, such as (1) the type of the disease-some cases progress to a fatal issue in spite of all treatment, (2) the social position and sex of the patients, (3) the stage of the disease when treatment is commenced, (4) the age of the patients-pulmonary tuberculosis in the young adult tends to shorten life much more markedly than when it occurs in or after middle life, (5) the circumstances of the patient after discharge-the character of his home surroundings, his own care of his health, the nature of his occupation, and the like. It is concluded that some fifty-seven per cent of male and sixty-seven per cent of female patients in the second stage of pulmonary tuberculosis survive, often with good working capacity, for five years or more ; a result which fully justifies the provision of sanatorium treatment Much important information is embodied in this Report upon such subjects as after-care and village settlements for the tuberculous, methods of diagnosis, and special forms of medical and surgical treatment.

\section{Science in the 'Sixties}

A pamphlet with this title by Sir Oliver Lodge forms one of a series edited by Mr. John Drinkwater and addressed to men of letters. In it Sir Oliver contrasts the indifference displayed by the public and the Press to scientific discoveries made in the 'sixties with the universal interest shown at the present time in such subjects as relativity and the constitution of the stars. For the science of the 'sixties, Sir Oliver confines himself almost entirely to the theory of the electromagnetic field brought forward by Maxwell as the mathematical interpretation of Faraday's lines of force. He uses the words 'juggled with' to describe the process by which Maxwell evolved the electromagnetic theory of light from his mathematical expressions. This seems to us an unfortunate choice of words, likely to produce a wrong impression on the minds of readers. The steady progress from Maxwell to present-day wireless is outlined, and Sir Oliver concludes by giving his opinions on current theories. The new doctrine of uncertainty he summarises in " the act of observing carries with it inevitably an act of perturbing", but he denies that this renders events unpredictable. By 'faith' only does he accept relativity, but wave mechanics "is a healthy infant of great promise"

\section{Scientific Apparatus of Historical Importance}

SEvEraL daily newspapers recently published a letter from the Institute of Physics over the signatures of Lord Rutherford and others asking for the co-operation of anyone possessing pieces of apparatus likely to be of historical importance. In 1925 the Institute of Physics appointed a committee to advise on the preservation of such apparatus. This committee is anxious to trace any pieces with which fundamental research in physical science has been carried out, and to arrange for their preservation. The committee has also entered upon the task of drawing up a catalogue of such pieces. Several pieces of great historical importance have already been secured for the nation and are now housed in the Science Museum at South Kensington, and the response to the recent letter has brought to light several other important pieces. Articles describing and cataloguing such pieces are published from time to time in the Journal of Scientific Instruments. Many readers of NATURE may have such apparatus in their possession or under their charge; and the Secretary of the Institute of Physies, 1 Lowther Gardens, Exhibition Road, London, S.W.7, will be grateful for any information that will assist in tracing such pieces or in completing the catalogue. For the benefit of future historians of physical science it is desirable to have as complete a record as is possible of the work of British physicists, and it is to this end that this task has been undertaken.

\section{Cremation and Population}

Mrs. Alec-Tweenie's address on "Cremation the World Over" at the Cremation Conference, which was held at Brighton on July 18-21, reinforced a strong appeal for the wider adoption of this method of disposal of the dead by reference to the distribution of the custom of burning the dead among peoples of antiquity and non-European races. She dwelt in particular on the practice of cremation among the Hindus, contrasting it in detail with the methods of burial among the Chinese, and pointing out how among the latter reverence for the last resting-places of the dead, where land enclosing burial mounds is under cultivation, hampers agriculture and is an increasing menace to food supply among a teeming population which already produces barely enough for its needs. The vastness of the population, it might be added, makes the practice increasingly detrimental from the point of view of hygiene. Although Mrs, Tweedie did not hesitate to make use of the appeal to the emotion which reflection on the conditions and consequences of inhumation never fails to arouse, a marked feature of her address was the emphasis with which she stressed the import of cremation as a factor in the world's population problem, linking it up with food supply and birth control in relation to over-population. As she put it in her closing words, "Without birth control and world cremation, what will the end be?" Mrs. Alec-Tweedie was the first and only woman on the council of the Cremation Society of England for more than ten years. She is the daughter of the late Dr. George Harley, F.R.S., of Harley Street, and her brother was Dr. Vaughan Harley. Her brother-inlaw is Dr. Francis Goodbody, who has done much work for the centenary meeting of the British Medical Association.

\section{Population of London}

THE volume of the Census, 1931, which covers the County of London has been published (London: H.M. Stationery Office, $3 s$. net). The total population enumerated in the City of London and the twenty- 